\title{
Discussion on Development Mode of Health Care Tourism
}

\author{
Liyuan Zhang \\ Miyi Housing and Construction Bureau, Panzhihua, China \\ Email: lyproper@hotmail.com
}

How to cite this paper: Zhang, L.Y. (2019) Discussion on Development Mode of Health Care Tourism. Journal of Service Science and Management, 12, 821-831. https://doi.org/10.4236/jssm.2019.127056

Received: November 5, 2019

Accepted: December 8, 2019

Published: December 11, 2019

Copyright $\odot 2019$ by author(s) and Scientific Research Publishing Inc. This work is licensed under the Creative Commons Attribution International License (CC BY 4.0).

http://creativecommons.org/licenses/by/4.0/

\begin{abstract}
Health care tourism is a new form and trend of tourism development in the new era, which not only meets the requirements of people's pursuit for healthy life quality, but also enriches the effective supply of elderly care products. Based on the perspective of industry integration, this paper conducts analysis on the present situation of health care tourism in China, analyses the development characteristics of health care tourism at the present stage through case study, then summarizes the development mode of health care tourism on this basis. Finally, this paper puts forward five innovative measures, characteristic brand, demonstration base, regional circle, professional team and top-level design to provide reference for the development of health care tourism.
\end{abstract}

\section{Keywords}

Health Care Tourism, Industry Integration, Development Mode

\section{Introduction}

Sub-health in China presents a younger and steady growth trend, which has become a hot topic at the moment in consideration of the problems such as the imbalance between the supply and demand of old-age care [1]. How to diverge thinking, jump out of the industry shackle and look for a sally port with the viewpoint of integrated development has become the key to solving the problem. Health care tourism is with a strong inclusiveness and extensibility, which not only meets the needs of people for a "deep breath" health journey by getting away from the city, but also provides a direction for enriching the supply of elderly care products [2].

\section{Current Situation and Typical Cases}

The development of health care tourism in China still stays in its initial stage. 
Based on the ever-increasing trend of aging and people's pursuit and yearning for a healthy life, the top-level design is highlighted from the national and local levels to escort the healthy and orderly development of health care tourism. In 2015, premier Li Keqiang put forward the healthy China strategy in the government work report and raised the theme of health to the national level, which opened the prelude to the integrated development of health care industry and tourism. Since then, the State Council and various ministries and commissions have issued several documents aimed at promoting the development of health care industry and tourism. From 2016 to 2018, the standards for health care tourism demonstration bases have been formulated successively to actively promote the construction of health care tourism demonstration bases and the development of health care tourism [3].

In the process of integrating resources and developing health care tourism, various regions have formed their own distinctive development patterns, setting a benchmark for health care tourism, such as the typical areas of Hainan province, Panzhihua city of Sichuan province and Bama county of Guangxi province [4].

\subsection{Hainan}

Under the general background of the health development strategy of China and the construction of international tourism island, Hainan took advantage of the climatic conditions and ecological resources to establish a "healthy Hainan" brand and four units have been successively approved to be constructed as the demonstration bases of national health tourism and traditional Chinese medicine health tourism since 2013, attracting a lot of health care tourists to visit and spend and realizing a tourism revenue of 81.199 billion yuan throughout the whole province in 2017 [5].

The two development characteristics of health care industry are as follows:

First, it highlights the characteristics and combines medical treatment and care to boost tourism development. With a good ecological environment, Hainan gives full play to the advantages of local tourism resources, improves infrastructure and enriches the types of product supply so as to attract a large number of "migratory bird elderly" from outside the province and the north to take Hainan as a tourist destination or sojourning place under the condition of insufficient supply of tourism products in winter. "Boao Lecheng International Medical Tourism Pilot Zone" constructed on this basis conforms to the needs of the elderly in medical treatment and health and carries out health management, licensed medical treatment, care and rehabilitation, medical beauty and other services. On this basis, it improves the health service facilities and system, encourages the construction of diversified health care institutions, promotes the improvement of health care insurance industry and boosts the settlement process of medical treatment in different places to provide convenience for tourists visiting for the purpose of prevention, treatment of diseases and rehabilitation. 
Second, it strengthens the industry integration and fosters new forms of health care tourism. Relying on the climatic conditions, marine resources, hot spring resources and minority culture, Hainan pays attention to the effective integration of the traditional medical treatment and health care skills of Li nationality with modern medicine, deepens the cooperation between tourism enterprises and medical institutions and creates a batch of high-quality tourism routes and industrial agglomeration areas with health and hot spring health maintenance as the theme. It should make efforts to build a TCM health care base centering on the cultivation of Chinese medicinal materials and drug research and development, rationally and effectively utilize marine resources, develop marine medicine and ecological health food and extend the health industry chain. In addition, the integration of tourism and sports should be strengthened and a series of international events represented by Hainan island international road cycling race and golf star race should be held to enhance the popularity and international influence of Hainan tourism brand.

\subsection{Sichuan}

Panzhihua city in Sichuan province develops the health care tourism industry relying on its resources such as high altitude, low latitude, annual average temperature of 20.3 degrees Celsius, 2300 - 2700 hours of sunshine all year around and high negative oxygen ion content. In 2014, it was approved to establish a "national-level health care industry development pilot zone" and build a brand image of "urban flower city and health care resort". In 2017, the tourism revenue of the whole city reached 27.931 billion yuan, contributing $35.2 \%$ to GDP [6].

The development characteristics of its health care industry are reflected as follows:

First, it accurately locates the target market and develops the "silver economy". Panzhihua city pays attention to the healthy development demand of aging population and develops the elderly market. Relying on the advantages of hospitals and other resources, it explores the cooperative development model between hospitals and elderly care service institutions, builds an integrated service platform for medical treatment and care, creates an integrated service system for the community in medical treatment and care, encourages and promotes the service innovation of elderly care institutions and the specialized construction of day-care centers and provides health care tourism beds for visiting tourists.

Second, it relies on resource advantages to boost industry integration. With pleasant climate, plenty of sunshine, more than 300 days of frost-free period, large temperature difference between day and night, various fruits and vegetables all year around, a national mango base with the northernmost latitude, the highest altitude, the best quality and the latest maturity, the province's largest thermophilic early spring vegetable base and a national-level recreational fishery base, it provides the guarantee for healthy diet. Relying on the advantages of the primary industry, Panzhihua city builds the development framework of leisure 
agriculture park and develops the health care agriculture park, health care summer camp and other integrated products of agriculture and tourism.

In addition, Panzhihua city pays attention to the integration exploration between the tertiary industries, accelerates the development of the sports industry and builds a national-level canoe slalom competition training base and other winter competition training bases, attracting more than 20 national, provincial, municipal and foreign sports teams to Panzhihua for competition and training every year on average, which focuses on building recreational fitness venues and holding nationwide fitness sports events to attract sports crowd from home and abroad to participate in sports and form a new development pattern of "health care+" [7].

\subsection{Guangxi}

With backward economy and beautiful mountains and clear waters, Bama in Guangxi province is a typical "old, minority, remote and poor" area, which is a national-level poverty-stricken county. However, the number of centenarians in this area is much higher than that of other regions, which attracts extensive attention from the international medical community. Through investigation and demonstration, Bama was officially recognized as the fifth longevity region in the world in 1991 by the international society of natural medicine, which opened the door of Bama to the development of longevity tourism. Bama makes use of its resource advantages of strong geomagnetic field, 2000 - 50,000 negative oxygen ions per cubic meter, weakly alkaline water with small molecules, long time of sunshine of far infrared ray and rich selenium, manganese, zinc and other trace elements in the soil for tourism development. In 2013, Bama was listed as one of the three major international tourism destinations in Guangxi and built Bama international tourism zone for longevity and health maintenance. In 2017, it received a total of 5.298 million domestic and foreign tourists, achieving a total tourism revenue of 4.758 billion yuan [8].

The development characteristics of Bama health care tourism are as follows:

First, it gives play to the role of tourism linkage and forms a health care industry chain. The local government makes great efforts to give full play to the linkage mechanism of "tourism+", and strengthens the integration of the primary and tertiary industries, develops featured products such as tourism and old-age care and extends the health care industry chain focusing on the production and sales of drinking water and the processing of featured agricultural and sideline products relying on the ecological resources and traditional agriculture. In addition, it highlights the government's leading role and has launched the relevant documents successively like "Implementation plan for the establishment of a health-care and old-age-care town in Bama Yao Autonomous County" and "Implementation plan for Bama Yao Autonomous County to fully liberalize the old-age service market and promote the old-age service quality" to promote the construction of local characteristic towns for health maintenance and old-age 
care tourism and integrated service institutions of leisure, medical treatment, health maintenance and old-age care.

On this basis, it is necessary to deeply explore the local ethnic culture and focus on creating a series of featured products such as ethnic medicine rehabilitation tourism and ethnic medicine culture experience, which not only manifests the charm of ethnic culture, but also unifies the purpose of tourists' visit and becomes the key to building a local town of TCM health tourism.

Second, it builds the image of health care brand and expands the popularity. Relying on the opportunity of permanent residence of China-ASEAN expo in Nanning, Bama, together with the former National Tourism Administration and the State Administration of Traditional Chinese Medicine, organized the China-ASEAN international forum for traditional medicine health tourism and obtained the permanent hosting qualification, which laid a foundation for the expansion of the international popularity and influence of Bama health care tourism. On this basis, Bama successfully registered the trademark of "longevity Bama" for all varieties of goods and services in 2016, which is complementary to the tourism image with "Renshou" as the core, making the government, enterprises, residents, tourists and other stakeholders enhance their awareness of the brand and achieve the purpose of marketing and promotion [9].

\section{Analysis of Development Mode}

By reviewing the experience of health care tourism in the case study, five development modes of health care tourism in China can be concluded as follows.

\section{1. "Forest and Tourism Integrated" Mode}

China is rich in mountain tourism resources, with a large forest coverage and high concentration of negative oxygen ions. At present, 181 cities have won the title of "national forest city" and 881 national forest parks are distributed in various provinces and regions. Forest resources not only regulate the urban temperature and balance the ecology, but also contain numerous rare species and valuable Chinese medicinal herbs, which provide the possibility for the areas rich in mountain resources to carry out summer recuperation function and medical science development and research [10]. Therefore, relying on the mountains and forests, it forms an industry chain-type development integrating medical treatment and care, builds a national-level forest health care tourism resort with the function of health care, improves the quality and level of tourism and forms a whole-area forest health care tourism brand supplemented by the forest parks in various administrative areas of each province with forest bath, yoga and meditation as the theme and heath care and medical research and development as the industry expansion terminal [11].

\section{2. "Agriculture and Tourism Integrated" Mode}

In the process of continuous urbanization, the number of migrant workers in 
various regions increases year by year, resulting in a continuous increase in the population of first-tier cities, while the number of permanent rural residents decreases sharply, the phenomena and problems such as left-behind children, empty-nest elderly and hollow villages are also increasingly prominent. The decline of rural areas makes the original farming culture and pastoral civilization no longer exist. In the report of the $19^{\text {th }}$ National Congress of the Communist Party of China, the strategy of rural revitalization was clearly put forward and industrial integration provided the direction for rural revitalization. It is necessary to combine agriculture with tourism, give play to the fundamental role of agriculture, form a two-hour high-speed railway tourism economic circle and life circle by virtue of the accessibility of high-speed railway and expressway with cities as the center of the circle and "return to innocence and nostalgia" as the purpose and make use of the good ecological environment, convenient traffic, friendly neighborhood atmosphere and idle rural housing and land resources to build an ecologically livable health care tourism town so as to attract different classes of consumer groups to experience the life of "sojourning for rural fun" [12].

Taking the tea industry in characteristic agriculture as an example, tea originated from China and has a long history of tea culture. As of the end of 2015, the planting area of tea gardens in China was 2.8917 million hectares and the number of tea consumers was 471 million. Although the output value of China's tea industry increased, it was still in the primary stage of tea sales and the problems like limited tea industry chain and single product structure still existed. Under the background of industry integration, it is necessary to integrate various links of the tea industry chain such as tea planting, tea picking, tea making and tea tasting by relying on the medicinal value of tea itself and centering on the tea ceremony to enhance the value transformation of tea. Besides, the reception and service facilities of the tea garden should be improved to create an experiential lifestyle of tea tour and highlight the characteristics of "slow life" and "quiet life", so that the health care tourists can be relieved from physical fatigue, relax themselves and improve their mental state.

\section{3. "Sports and Tourism Integrated" Mode}

According to the data in "Healthy China 2030 Planning Outline", the health literacy level of Chinese residents was only $10 \%$ in 2015 , which indicates that residents had a low ability to acquire and apply health knowledge to maintain, manage and form a healthy lifestyle. However, with the advent of the era of aging and the trend that chronic diseases are becoming more prevalent among a younger age group, the government, society and residents have realized the importance of health, the national fitness concept is deeply rooted in the hearts of the people and the mobile phone step-counting APP, clock in sports, sports challenge, city marathon activities become popular among people, which also provides the conditions for the integration of sports and tourism. Relying on the 
landscape tourism resources, it can build waterfront riding greenway, wading trails, highway and plank road surrounded by mountains and other rotary roads for sightseeing and health care, carry out specific sports like mountaineering, rock climbing, gliding and low-level tourism, create influential national and provincial high-quality sports events, strengthen the concept of healthy life relying on sports events and construct the demonstration base of national sports tourism so as to promote the joint development of sports and tourism [13].

\section{4. "Medical and Tourism Integrated" Mode}

According to the data of National Bureau of Statistics, the old people aged 60 and above in China reached 240 million in 2017, accounting for $17.3 \%$ of the total population. In addition, the ageing speed of population has quickened and there is a strong demand for old-age care and medical services; therefore, it is necessary to build a sojourning base integrating medical treatment and care, combine the rich resources of traditional Chinese medicine and national medicine therapy of China with the longevity culture, build an old-age care and tourism town and hot spring health resort, form the characteristic health care tourism products such as TCM life cultivation and health preservation, national medical treatment system and hot spring SPA and improve the medical prevention and treatment service system on the basis of the existing medical resources of China. At the same time, it should take sub-healthy people as the target market and fit in with the concept of preventive treatment of diseases by traditional Chinese medicine to innovate health care tourism products, inherit and activate the medical skills of ethnic minorities, develop positive and healthy habits and create a "light and simple" lifestyle with traditional Chinese medicine diet and ethnic medicine culture as the theme [14].

\section{5. "Culture and Tourism Integrated" Mode}

The national statistic data show that the cultural industries contributed $4.2 \%$ to the national economy by the end of 2017. In the process of promoting consumption and optimizing the industrial structure, the deep integration between the tertiary industries provides impetus for the economic development of China and the integration of culture and tourism among the "five happiness industries" is full of vitality and market value [15]. In the development of culture and tourism-integrated products, culture is the soul, which deepens the level and connotation of tourism and tourism is the carrier, which expands the industry chain. It is to rely on the traditional excellent culture and core socialist values in the new era to show the depth, breadth and decorous feeling of culture, enrich the spiritual world of tourists, improve the level of their cultural accomplishment and thus achieve the progress of the level from physical health maintenance to spiritual nourishing with local cultures as the characteristic on the basis of ensuring the physical health of consumers to develop the culture and tourism-integrated health care tourism products according to the local conditions [16]. 


\section{Innovation of Development Mode}

By analyzing the five development modes of health care tourism, it is summarized that appropriate methods can be taken for improvement. The industry should establish the image of health care tourism, make use of the information technology to construct a smart health care tourism base, deepen regional cooperation, perfect the health care talent cultivation system and strengthen the top-level design and other innovative development paths to upgrade the development mode of health care tourism.

\subsection{Characteristic Brand}

Tourism image is the extraction of the characteristics and essence of tourism destinations and plays a key role in the decision-making of tourists, which is an important link of tourist marketing and promotion. Tourism destinations should excavate the health care attributes and cultural characteristics of local resources and get them sublimated to the tourism image that is known to the public to attract the tourists to visit and form a word-of-mouth effect in the process of developing health care tourism products. Taking Bama in Guangxi province as an example, the local government makes great efforts to build a longevity culture and takes "blessing from heaven and earth, Renshou, Bama" as the tourism image to build a whole-area health care tourism product chain, integrate the ecological health food such as semen cannabis oil and Bama miniature pig and the health care scenery belt of Panyanghe into the health care tourism image and shape the health care tourism brand.

\subsection{Demonstration Base}

It is necessary to actively explore the construction path of smart tourism service system and its application scope, construct the online service platform based on network information technology, integrate the information of six elements of tourism, provide information consultation, complaint handling and supervision services, build the smart health care service module, establish the medical treatment and health indicator monitoring center on the basis of "Internet+", form the recreation and health care system of online appointment, diagnosis and treatment and dedicated medical staff, provide custom rehabilitation projects, analyze and apply the information of recreation consumers through big data and innovate the health care service mode.

\subsection{Regional Circle}

There are rich types of tourism resources in China and it does not lack of high-quality monopolized resources in various regions. In the development of health care tourism, it is necessary to make precise positioning through the integration of resources to highlight local attributes and ethnic characteristics such as Chinese herbal medicine resources in various parts of China and the diagnosis and treatment skills of ethnic minorities represented by Yao doctors and medi- 
cine so as to avoid blind duplicated development. Each region should break through the boundaries of administrative divisions, create a coordinated development atmosphere through the government, strengthen policy support, deepen cooperation and connection in tourist sources, medical resources, information technology, professional talents, system and institution, etc., give play to the regional linkage mechanism and build an ecologically livable health care tourism circle.

\subsection{Professional Team}

The construction of professional talent team is the basis of health care services and it should focus on promoting the higher education institutions to set up health care-related majors and establish the curriculum system with rehabilitation and old-age service as its core to form the cultivation framework of skilled talents in TCM health care, hairdressing, SPA and nursing, etc., increase the investment in skills training funds, attach great importance to the improvement of professional skill level and form a talent attraction strategy combining government support, enterprise leading and community participation. In addition, it is necessary to establish the service standards for health care tourism with skills as the core and services as the feature, strengthen the training of service consciousness of skilled personnel, build a volunteer service center with certain knowledge of health and medical care, optimize the quality of health care tourism service and enhance the tourism experience.

\subsection{Top-Level Design}

From the national level, although some documents have been promulgated to promote the development of health industry, the policies are mostly aimed at the branch areas of health care industry, which lack of instructions for the overall planning. Besides, the local government has an insufficient understanding of the development of health care tourism and only a few areas regard health care industry as the local strategic development, resulting in the slow development of health care tourism in the provincial and municipal level, while health care tourism is a reflection of people's good wishes for longevity and health and also provides diversified thinking for relieving the mismatches between supply and demand for old age care, which is a product that is in line with the market demand law and social development requirements. In view of this, it is necessary to strengthen the top-level design of health care tourism on the existing basis, attach great importance to the construction of public innovation platform, encourage and correctly guide the private and social capital to enter into the health care industry, promote the deep integration of medical treatment, agriculture, industry and tourism, etc., optimize the public service system and form join forces in boosting the development of local economy.

\section{Conclusion}

Health care tourism is having progressive development in China. This trend is 
unstoppable and necessary. Secondary problems such as ecological environment destruction and air pollution are constantly emerging in China while the economy is undergoing transformation and development. Thus, blue sky and green water have become the yearning of people in their heart. The solution, health care tourism, can be both environmental-friendly and economy-boosting. Therefore, it is of great significance to explore the development mode and path of health care tourism in China from the perspective of industry integration.

\section{Conflicts of Interest}

The author declares no conflicts of interest regarding the publication of this paper.

\section{References}

[1] Hall, M. (2011) Health and Medical Tourism: A Kill or Cure for Global Public Health? Tourism Review, 66, 4-15. https://doi.org/10.1108/16605371111127198

[2] Lee, C.G. (2010) Health Care and Tourism: Evidence from Singapore. Tourism Management, 31, 486-488. https://doi.org/10.1016/j.tourman.2009.05.002

[3] Huang, L.Y. (2014) A Cultural Perspective of Health and Wellness Tourism in China. Journal of China Tourism Research, 10, 493-510. https://doi.org/10.1080/19388160.2014.951752

[4] Ren, X.Y. (2016) Health Tourism: Connotation Analysis and Development Path. Tourism Tribune, 31, 1-4.

[5] Huang, H. (2016) Study on the Coastal Healthy Tourism Industry under the Background of "One Belt One Way". Journal of Central South University of Forestry Science and Technology, 10, 77-80.

[6] Liu, Y., He, X.D. and Ma, R. (2015) Study on the Evaluation and Development Mode of Tourism Resources in Sichuan. Contemporary Tourism, 6, 18-22.

[7] Li, Z.X. (2015) Study on the Countermeasures to Strengthen the Construction of Sunshine Healthy Soft Environment in Panzhihua. Journal of Panzhihua University, 32, 8-11.

[8] Wang, Z.P., Xue, K., Zhang, Y. and Song, S.F. (2017) Analysis on the Development Path of Characteristic Towns in China. Study and Practice, 4, 23-30.

[9] Liang, K. and Du, J.C. (2015) Study on the Development Mode of Modern Industrial Tourism from the Perspective of Industrial Integration. World Regional Studies, 24, 152-159.

[10] Xie, W.C., Li, X.M. and Xiang, X. (2018) Study on the Spatial Distribution and Its Optimization of Health Tourism Destinations in Wuhan. Journal of Central China Normal University, 52, 147-154.

[11] Zhou, Y.B. (2016) Exploration on Forest Health Tourism. Ecological Environment and Protection, 5, 205-206.

[12] Meng, T.X. (2018) Research on the Integration Mode and Development Strategy of Tourism and Agriculture. Business Economy, 12, 37-41.

[13] Zhao, H. and Yu, J. (2015) Research on the Integration of Rural Tourism and Cultural Creative Industries in the New Normal. On Economic Problems, 4, 50-55.

[14] Ma, J. (2005) Discussion on the Theory of Industrial Convergence Identification. Social Science Journal, 3, 86-89.Wu, G.A. and Zheng, X.M. (2017) Discussion on 
the Development Mode of Health Tourism in China. Modern Regimen, 3, 294-298.

[15] Liu, S.Y. (2018) A Brief Research on the Integration of Culture and Health Tourism Industry. Contemporary Tourism, 9, 74-75.

[16] Wu, G.A. and Zheng, X.M. (2017) Discussion on the Development Mode of Health Tourism in China. Modern Regimen, 3, 294-298. 